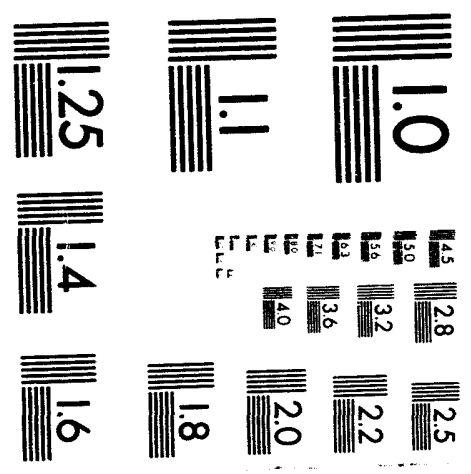




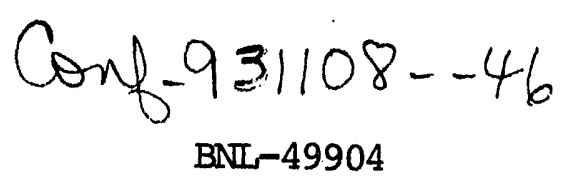

\title{
ION BEAM-ASSISTED DEPOSITION OF BORON NITRIDE FROM A CONDENSED LAYER OF DIBORANE AND AMMONIA AT $78 \mathrm{~K}$
}

\author{
R. J. Kroczynski*, D. R. Strongin*, M. W. Ruckman** and M. Strongin** \\ *The State University of New York at Stony Brook, Department of Chemistry, \\ Stony Brook, New York 11794 \\ **Physics Department, Brookhaven National Laboratory, \\ Upton New York 11973
}

\begin{abstract}
This paper examines the ion beam-assisted deposition (IBAD) of thin boron nitride films using cryogenically condensed precursors. Low energy $(1100 \mathrm{eV})$ argon and $(2000 \mathrm{eV})$ deuterated ammonia beams with currents of $600-850 \mathrm{nA}$ were used to mix and initiate reactions in frozen $(90 \mathrm{~K})$ layers of diborane $\left(\mathrm{B}_{2} \mathrm{H}_{6}\right)$ and ammonia $\left(\mathrm{NH}_{3}\right)$ or only $\mathrm{B}_{2} \mathrm{H}_{6}$, respectively. The resulting film is shown to be an amorphous BN coating approximately $30 \AA$ thick.
\end{abstract}

\section{INTRODUCTION}

Boron nitride has interesting and useful mechanical, electrical, and chemical properties. Thin films of this material have been produced in a variety of ways. [1] Boron nitride is analogous to carbon, regarding its solid phases. It exists in a diamond-like cubic phase, two graphitic hexagonal phases and an amorphous phase. $[2,3,4]$

This work demonstrates a new means of producing an amorphous or hexagonal BN thin film. The technique involves condensing gaseous precursors onto a cryogenically cooled (90$100 \mathrm{~K})$ substrate and initiating film growth with a low energy (1-2 keV) ion beam. [5] Film growth should only occur where the adsorbed layer is exposed to the ion beam. The unreacted materials desorb upon warming to room temperature leaving behind a clean surface. This provides a means for the selective deposition of the coating. [6] The low temperatures avoid problems during film growth with the thermally induced diffusion inherent in chemical vapor deposition (CVD), or plasma-enhanced CVD normally used to make BN films.

In this study, the film was characterized with $\mathrm{x}$-ray photoelectron spectroscopy (XPS), reflectance Fourier transform infrared spectroscopy (FTIR) and high resolution transmission electron microscopy (HRTEM). Those techniques provide information about the composition, chemical environment, bonding, phase, and thickness of the film.

\section{EXPERIMENTAL DETALS}

The substrates used were $n$-doped Silicon $\langle 100\rangle$ single crystal wafers and platinum coated glass slides cut to $1 " \times 1 / 2$ " chips. They were mounted onto a sample stage attached to 
a cryostat which was cooled with liquid nitrogen; attaining temperatures of $90-100 \mathrm{~K}$. To monitor the temperature a chromel-alumel thermocouple was spotwelded to one of the molybdenum plates clamping down the sample. The gasses used were a $5 \%$ diborane $\left(\mathrm{B}_{2} \mathrm{H}_{6}\right) / 95 \%$ argon $(\mathrm{Ar})$ mixture, anhydrous deuterated ammonia $\left(\mathrm{ND}_{3}\right)$, anhydrous ammonia $\left(\mathrm{NH}_{3}\right)$, and argon (Ar). The gasses were introduced into the ch mber through one of two dose tubes regulated by leak valves or through the exit aperture of $L e$ ion source.

The ion beam was generated by a Colutron ion source, focussed with an Einzel lens, and mass selected using a Wein filter with a resolution of 1 AMU. The beam passed through an 8 $\mathrm{mm}$ diameter exit aperture before striking the substrate. Typical ion beam currents were 600 $850 \mathrm{nA}$ as measured at the sample. This gives an arrival rate of $7.5 \times 10^{12}-1.1 \times 10^{13} \mathrm{ions} / \mathrm{cm}^{2}-\mathrm{s}$ with a typical exposure time of 900 seconds per spot. The entire assembly could be valved off from the main chamber and pumped separately with a $360 \mathrm{l} / \mathrm{s}$ turbo pump. The base pressure in that configuration was $1 \times 10^{-8}$ Torr.

Film deposition and XPS were conducted in a stainless steel ultra high vacuum (UHV) chamber. The main chamber was pumped with a $110 \mathrm{1} / \mathrm{s}$ turbo and $400 \mathrm{l} / \mathrm{s}$ ion pump to a base pressure of $5 \times 10^{-9}$ Torr as measured with a nude Baynard-Alpert ionization gauge. A UTI residual gas analyzer showed the pressure largely due to hydrogen, water, and $\mathrm{CO}$ gasses. Some hydrocarbons were also detected.

The films were characterized in situ by XPS using $\mathrm{Mg} \mathrm{K} \alpha$ X-rays. The electron energy analysis was done with a hemispherical analyzer using a constant pass energy of $50 \mathrm{eV}$. Spectra were referenced to the Fermi level using the $\mathrm{Pt} 4 \mathrm{f}$ core levels. The films deposited on the platinum coated slides were also characterized by Reflectance FTIR from $4000 \mathrm{~cm}^{-1}$ to $400 \mathrm{~cm}^{-1}$ with $4 \mathrm{~cm}^{-1}$ resolution on a Mathson Cygnus 100 spectrometer. Cross sectional HRTEM was done on one coated silicon sample using a $200 \mathrm{kV}$ JEOL $2000 \mathrm{fx}$ TEM.

A difficulty encountered with ion beam processing is sputtering of the condensed layer and deposited film. To offset this removal of reactants from the surface, $1 \times 10^{-7}$ Torr $\mathrm{NH}_{3}$ and $1 \times 10^{-6}$ Torr $\mathrm{B}_{2} \mathrm{H}_{6}$ partial pressures were maintained in the vacuum chamber during $\mathrm{Ar}^{+}$ion beam exposure.

\section{RESULTS AND DISCUSSION}

Figure 1 shows the change in the boron 1 s core level as the film is condensed and processed. The lowest spectra shows the B 1s peak positioned at $191.3 \mathrm{eV}$ for cocondensed $\mathrm{B}_{2} \mathrm{H}_{6}$ and $\mathrm{NH}_{3}$. Exposure to the $1100 \mathrm{eV}$ argon ion beam caused a 50\% reduction in peak height and a shift to 190.8 eV. Upon warming to room temperature the peak height increased slightly and was

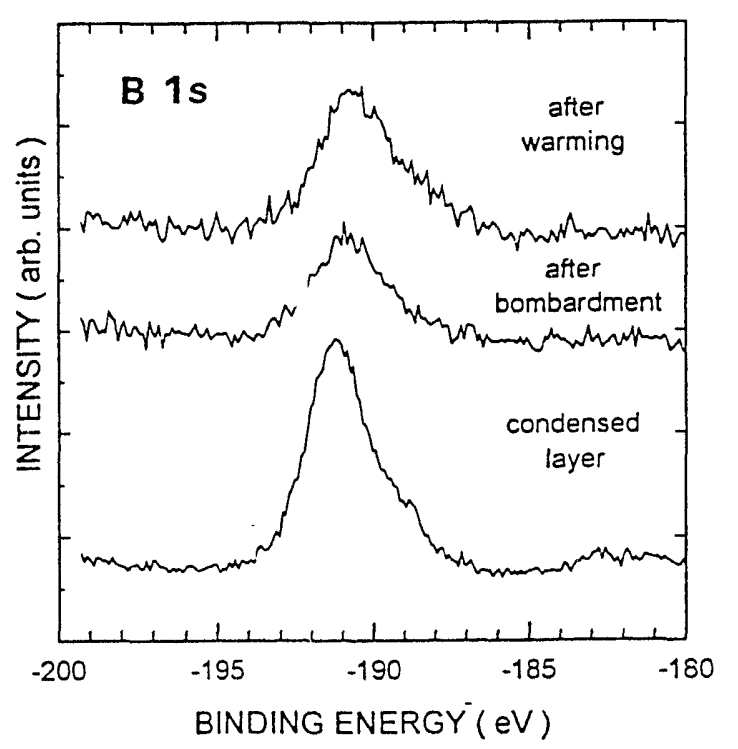

Figure 1. B 1s spectra for the processing of the mixed layer of $\mathrm{B}_{2} \mathrm{H}_{6}$ and $\mathrm{NH}_{3}$. 
positioned at $190.3 \mathrm{eV}$. The final $\mathrm{B}$ 1s binding energy is in good agreement with literature values for $\mathrm{BN}$. [7] This peak, however, shows a shoulder extending to 188 $\mathrm{eV}$ suggesting some solid hydrogenated boron was also deposited. There is no evidence of boron oxide $\left(\mathrm{B}_{2} \mathrm{O}_{3}\right)$ at $193.4 \mathrm{eV}$ or boron carbide $\left(\mathrm{B}_{4} \mathrm{C}\right)$ at $186.4 \mathrm{eV}$. Runs conducted without exposure to the ion beam show a clean surface with no detectable boron after warming to room temperature.

Figure 2 shows the corresponding changes in the nitrogen 1s core level. The initial position for the $\mathrm{N} 1 \mathrm{~s}$ level in the cocondensed layers was $400.3 \mathrm{eV}$. After argon ion bombardment the peak broadens with the formation of a large shoulder situated $a^{+}$ $388.5 \mathrm{eV}$. Warming causes the feature at $400.3 \mathrm{eV}$ to diminish greatly leaving an asymmetric peak situated at $388.3 \mathrm{eV}$. This is a slightly higher binding energy than reported literature values for $\mathrm{BN}$ of 387.9 eV.[8] Depositions involving deuterated ammonia ion bombardment exhibited similar changes.

For infrared spectroscopy, thicker samples were needed. To increase the thickness of the final coating six depositions were done on each substrate. Figure 3 shows an absorbance spectra for our film produced by ion beam-assisted deposition (IBAD), (lower curve) and a CVD deposited film several microns thick (upper curve). The lower spectra has been magnified by a factor of 40 . Both spectra contain IR absorption bands that can be assigned to $\mathrm{B}-\mathrm{N}, \mathrm{B}-\mathrm{H}$, and $\mathrm{N}-\mathrm{H}$ bonding. [9] The B-N absorption band appears near $1465 \mathrm{~cm}^{-1}$ in the lower spectrum for the IBAD film and at $1370 \mathrm{~cm}^{-1}$ for the CVD grown film. The literature shows a range of values for amorphous and hexagonal B-N phases and places this absorbance feature near $1400 \mathrm{~cm}^{-1}$ with a companion peak at $800 \mathrm{~cm}^{-1}$. [10] It should also be noted that high resolution electron energy loss

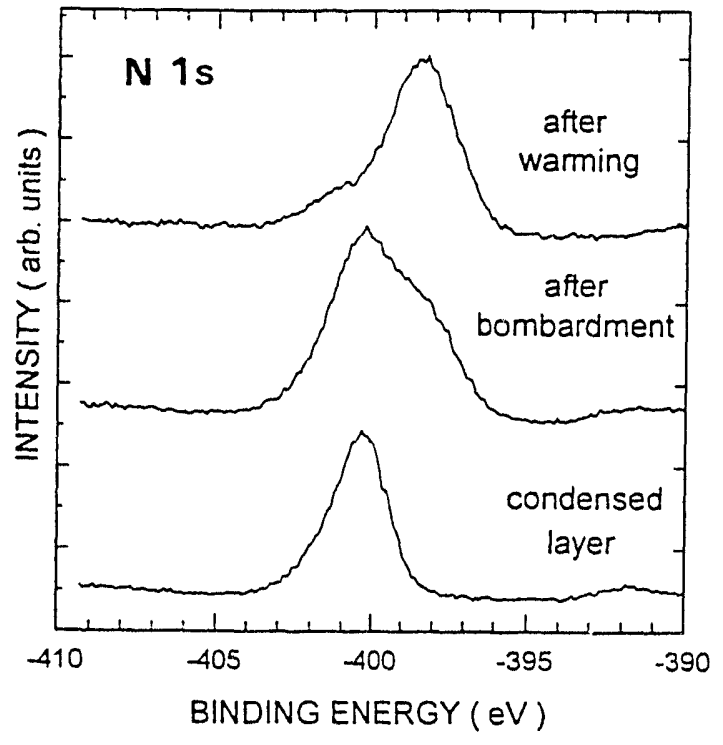

Figure 2. $\mathrm{N}$ 1s spectra for the processing of the mixed layer of $\mathrm{B}_{2} \mathrm{H}_{6}$ and $\mathrm{NH}_{3}$.

RECEIVED FEB $O 41994$ OSTI

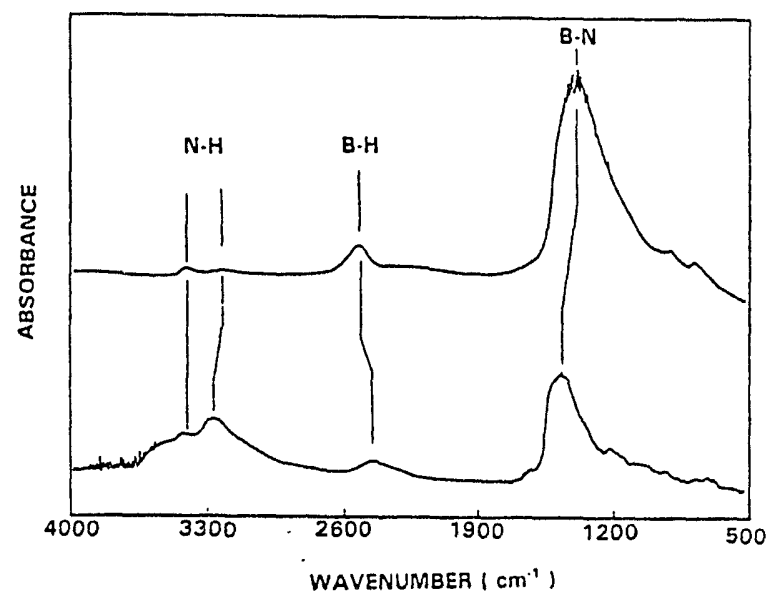

Figure 3. FTIR absorbance spectra for the IBAD film, magnified 40x, (lower) and a thick CVD BN film (upper). 
spectroscopy (HREELS) data for borazine (which also contains $\mathrm{B}-\mathrm{N}$ bonding) on platinum shows a $\mathrm{B}-\mathrm{N}$ band at $1465 \mathrm{~cm}^{-1}$ assigned to an in-plane assymetric ring streching mode. [11] However, it would be difficult to explain how a monolayer of borazine would produce such a strong IR signal. Our B-H band is weak and broad and positioned roughly at $2450 \mathrm{~cm}^{-1}$. The reference spectra and the literature values for this feature lie near $2500 \mathrm{~cm}^{-1}$. Finally, our film's two $\mathrm{N}-\mathrm{H}$ bands appear at $3265 \mathrm{~cm}^{-}$ ${ }^{1}$ and $3425 \mathrm{~cm}^{-1}$. This is in good agreement with both the reference spectra and literature values. [12] Figure 4 shows IR transmission spectra for films deposited by $2000 \mathrm{eV} \mathrm{ND}$ , $1100 \mathrm{eV} \mathrm{Ar}{ }^{+}$mixing of $\mathrm{NH}_{3}$ and $\mathrm{B}_{2} \mathrm{H}_{6}$ layers, and $1100 \mathrm{eV} \mathrm{Ar}^{+}$bombardment of co-condensed layers, respectively. It can be seen that they have almost identical peak positions. All three show the B-N peak at $1465 \mathrm{~cm}^{-1}$ while the upper two spectra show the $\mathrm{B}-\mathrm{H}$ absorption bands at $2500 \mathrm{~cm}^{-1}$.

Figure 5 is a HRTEM photograph of the surface of the film. HRTEM was used to determine the degree of crystallinity and thickness of the BN film produced by the IBAD procedure. The film was found to be amorphous and 60-70 $\AA$ thick This suggests that each deposition produced a film 30-35 $\AA$ thick. This was in agreement with estimates obtained using substrate XPS core level attenuation.[13]

\section{CONCLUSIONS}

Argon or ammonia ion bombardment of condensed layers of ammonia and diborane or diborane, respectively, can be used to produce thin amorphous or hexagonal boron nitride coatings on a variety of substrates. Unexposed ammonia and diborane desorb upon warming to ambient temperatures leaving behind a clean surface. This characteristic makes the technique useful for

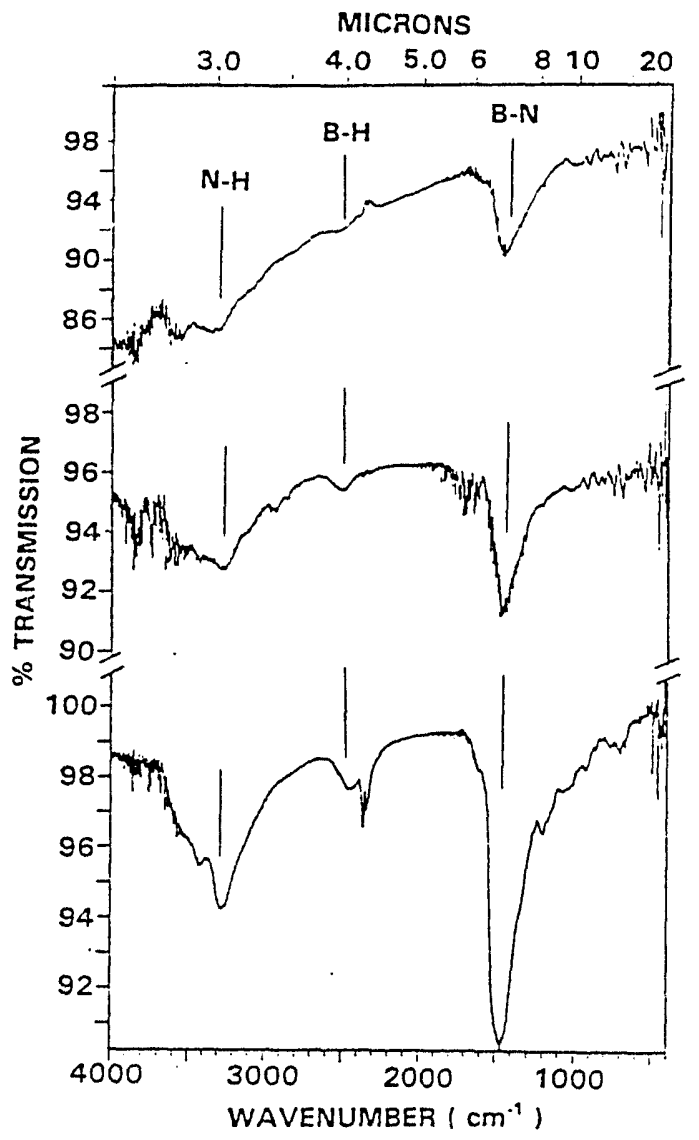

Figure 4. FTIR transmission spectra for 3 IBAD films. (Upper) an $\mathrm{ND}_{3}$ beam striking a condensed $\mathrm{B}_{2} \mathrm{H}_{6}$ layer; (middle) an Ar beam striking a layer of $\mathrm{NH}_{3}$ condensed on top of a layer of $\mathrm{B}_{2} \mathrm{H}_{6}$; (bottom) an $\mathrm{Ar}$ beam striking a mixed layer of $\mathrm{NH}_{3}$ and $\mathrm{B}_{2} \mathrm{H}_{6}$.

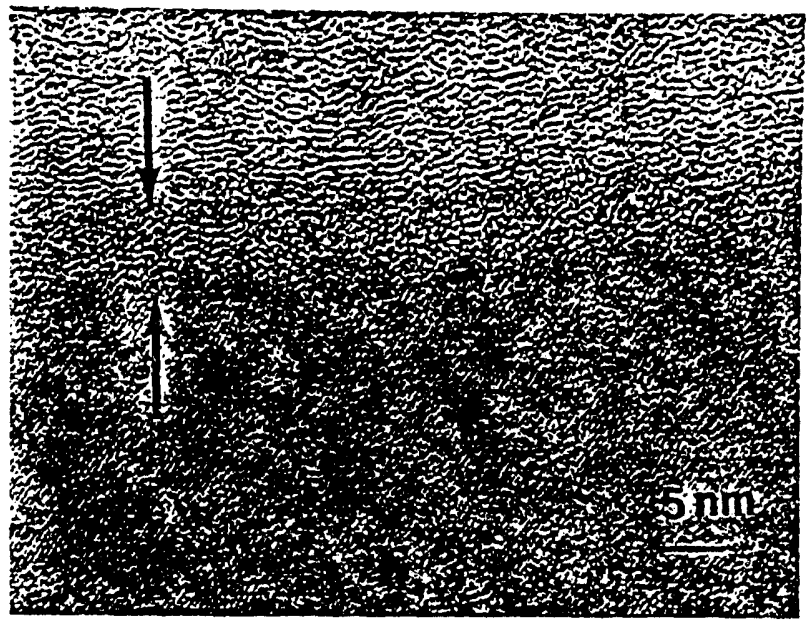

Figure 5. HRTEM image of IBAD BN film. 
site selective deposition of this material. This represents further development of previous work [14]; but more needs to be done to make this a usable fabrication process.

\section{ACKNOWLEDGMENTS}

R.J. Kroczynski thanks X.Q. Yang; Department of Material Science, Brookhaven National Laboratory, for his time and effort in obtaining the Infrared spectra; D. Gillette for his instruction and help in preparing the TEM sample, $R$. Sabatini for his work in obtaining the HRTEM images, J. Warren; Instrumentation Department, Brookhaven National Laboratory, for the SEM images, and R. A. Levy; Department of Physics, NJT, for the CVD boron nitride sample. This work was supported by the U.S. Dept. of Energy, Materials Sciences Division under Contract No. DE-AC02-76CH00016. RJK and DRS acknowledge support from the NSF ( DMR \#9258544).

\section{REFERENCES}

[1] P.S. Arya and M. D'Amico, Thin Solid Films, 157, 267, (1988)

[2] D.J. Kester, K.S. Ailey, and R.F. Davis, J. Mater. Res., 6, 1213, (1993)

[3] A.N. Pilyankevich and Nils Claussen, Mat. Res. Bull., 13, 413, (1978)

[4] Katsumitsu Nakamura, J. Electrochem. Soc., 132, 1757, (1985)

[5] D.R. Strongin, J.K. Mowlem, M.W. Ruckman, and M. Strongin, Appl. Phys. Lett., 60, 2561, (1992)

[6] D.R. Strongin, J.F. Moore, M.W. Ruckman, and M. Strongin, Mat. Res. Symp. Proc. Vol 282, 631, (1993)

[7] "Handbook of X-ray Pho toelectron Spectroscopy", Perkin-Elmer Corporation, (1978)

[8] N. Tanabe and M Iwaki, Nucl. Instr. and Meth B, 80/81, 1349, (1993)

[9] B. Rother, H.D. Zscheile, C. Weissmantel, C. Heiser, G. Holzhüter, G. Leonhardt, P. Reich, Thin Solid Films, 142, 83, (1986)

[10] D.J. Kester and R. Messier, J. Appl. Phys., 72, 504, (1992)

[11] R.J. Simons, M.T. Paffet, M.E. Jones, and B.E. Koel, Surface Science, 29, 254, (1991)

[12] R.A. Levy, D.J. Resnick, R.C. Frye, and A.W. Yanof, J. Vac. Sci. Technol., B6, 154, (1988)

[13] see Ref. 5

[14] M.W. Ruckman, J.K. Mowlem, J.F. Moore, D.R. Strongin, and M. Strongin, Mat. Res. Soc. Symp. Proc. Vol. 279, 651, (1993)

\section{DISCLAIMER}

This report was prepared as an account of work sponsored by an agency of the United States Government. Neither the United States Government nor any agency thereof, nor any of their employees, makes any warranty, express or implied, or assumes any legal liability or responsibility for the accuracy, completeness, or usefulness of any information, apparatus, product, or process disclosed, or represents that its use would not infringe privately owned rights. Reference herein to any specific commercial product, process, or service by trade name, trademark, manufacturer, or otherwise does not necessarily constitute or imply its endorsement, recommendation, or favoring by the United States Government or any agency thereof. The views and opinions of authors expressed herein do not necessarily state or refleci those of the United States Government or any agency thereof. 
